\title{
BMJ Open Remote monitoring of marginalised populations affected by COVID-19: a retrospective review
}

\author{
Stephanie Q Ko (D) , ${ }^{1}$ Benjamin M Y Hooi, ${ }^{1}$ Chieh-Yang Koo, ${ }^{2}$ Daniel W P Chor, ${ }^{3}$ \\ Zheng Jye Ling, ${ }^{4}$ Yen-Lin Chee, ${ }^{5}$ Wei-Ying Jen (i) ${ }^{5}$
}

To cite: Ko SQ, Hooi BMY, Koo C-Y, et al. Remote monitoring of marginalised populations affected by COVID-19: a retrospective review. BMJ Open 2020;10:e042647. doi:10.1136/ bmjopen-2020-042647

- Prepublication history and additional materials for this paper is available online. To view these files, please visit the journal online (http://dx.doi. org/10.1136/bmjopen-2020042647).

Received 13 July 2020

Revised 07 December 2020

Accepted 22 December 2020

\section{Check for updates}

(c) Author(s) (or their employer(s)) 2020. Re-use permitted under CC BY-NC. No commercial re-use. See rights and permissions. Published by BMJ.

${ }^{1}$ Division of Advanced Internal Medicine, University Medicine Cluster, National University Hospital, Singapore

${ }^{2}$ Department of Cardiology, National University Heart Centre, Singapore

${ }^{3}$ Department of Emergency Medicine, National University Hospital, Singapore ${ }^{4}$ Department of Medical Informatics, National University Health System, Singapore

${ }^{5}$ Department of HaematologyOncology, National University Cancer Institute, Singapore

Correspondence to Dr Wei-Ying Jen; wei_ying_jen@nuhs.edu.sg

\section{ABSTRACT}

Objectives The COVID-19 outbreak in Singapore has largely centred around migrant worker dormitories, comprising over $90 \%$ of all cases in the country. Dormitories are home to a culturally and linguistically distinct, low-income population, without on-site healthcare after-hours. The primary objective of this study was to assess the engagement and utilisation of a simple, lowcost, accessible, mobile health solution for remote selfreporting of vital parameters in dormitory residents with COVID-19.

Design Retrospective review of medical care.

Setting Two large migrant worker dormitories with a combined population of 31546 .

Participants All COVID-19-affected residents housed in dormitories during the study period.

Intervention All residents were taught to use a chat assistant to self-report their temperature, heart rate and oxygen saturations. Results flowed into a dashboard, which alerted clinicians of abnormal results.

Outcomes The primary outcome measure was engagement rate. This was derived from the total number of residents who registered on the platform over the total number of COVID-19-affected residents in the dormitories during the study period. Secondary outcome measures included outcomes of the alerts and subsequent escalations of care.

Results 800 of the 931 COVID-19-affected residents (85.9\%) engaged with the platform to log a total of 12511 discrete episodes of vital signs. Among 372 abnormal readings, 96 teleconsultations were initiated, of which $7(1.8 \%)$ were escalated to emergency services and 18 (4.9\%) were triaged to earlier physical medical review on-site.

Conclusions A chat-assistant-based self-reporting platform is an effective and safe community-based intervention to monitor marginalised populations with distinct cultural and linguistic backgrounds, living communally and affected by COVID-19. Lessons learnt from this approach may be applied to develop safe and cost-effective telemedicine solutions across similar settings.

\section{INTRODUCTION}

The COVID-19 pandemic has caused global devastation. After months of successfully controlling the outbreak within Singapore,

\section{Strengths and limitations of this study}

This is one of the few studies published in the setting of migrant worker dormitories affected by COVID-19.

- Data were collected across two different dormitories with a large number of residents.

- A control group was not available.

- Clinical outcome of residents transferred out of the dormitories was not available.

- There was little information about the experience of dormitory residents with the platform to explain the high engagement.

a surge of cases occurred among migrant workers, accounting for $94 \%$ of the 37183 cases. ${ }^{1}$ Many of the 400000 workers reside in migrant worker dormitories. The population density and the sharing of facilities in such dormitories make safe distancing measures difficult to impose. To stop further spread, the government imposed universal stay-home notices and converted larger dormitories into isolation facilities with access controls. ${ }^{2}$ To avoid overwhelming hospital resources, it became necessary to manage residents with COVID-19 within their dormitories. Public Health Institutions deployed healthcare teams to dormitories during the day, but there was no on-site presence at night. It was thus critical to develop a strategy to ensure that residents with COVID-19 were appropriately monitored for clinical deterioration ${ }^{3} 4$ throughout the course of their illness.

COVID-19 has propelled the use of telemedicine. ${ }^{5}$ Digital technologies including wearables, Bluetooth-enabled devices and phone applications have been developed and successfully used for remote self-monitoring of patients with COVID-19. ${ }^{6}$ However, these were implemented within regions of high technology literacy. To successfully introduce these technologies within the dormitory setting, we had to address the diversity in language and technological literacy within 
this population. Although the working language in Singapore is English, most migrant workers only speak their native language-mainly Bengali, Tamil, Mandarin or Hindi. The different social and cultural backgrounds also meant variable understanding of the use and intent of technology. Building trust in technology within a pandemic, where ever-changing information often raises uncertainty and fear, was exceptionally challenging.

With these challenges in mind, we designed and implemented an intuitive solution for remote self-reporting of vital signs. Our hypothesis was that a simple, interactive chatbot app, accessible in multiple languages and integrated with medical workflows, would allow for rapid adoption with high compliance to enable detection of residents at risk of deterioration. We also hope to share the lessons we learnt during the development process, to help others mitigate the complex challenges that we encountered.

\section{METHODS}

We performed a retrospective review on the engagement of migrant workers with a remote vital sign monitoring (VSM) system. The system was implemented sequentially in two large migrant worker dormitories in Singapore affected by COVID-19. Data were collected from 1 May 2020 to 26 May 2020.

\section{Setting}

This study was conducted in two of the five dormitories under the care of our institution. These were the largest dormitories, and thus had the most pressing logistical challenges to the provision of healthcare. Migrant worker dormitories are multistorey communal living facilities, with as many as 10 rooms per floor and 12-16 individuals per room in bunkbeds, with communal toilets and cooking facilities. Cooking facilities were closed during the COVID-19 period and cooked meals were provided. Wi-Fi was made available for free within the dormitories, and residents were provided with subscriber identification module (SIM) cards containing $50 \mathrm{~GB}$ of cellular data. All infected residents were isolated in designated isolation areas within the dormitory and were completely separated from uninfected residents. No other individuals were allowed into these isolation areas, except for identified staff wearing full personal protective equipment.

\section{Participant selection}

All infected residents in isolation areas were included. There were no exclusion criteria. Residents were removed from the monitoring system if they were transferred out of the dormitories (e.g., to acute care hospitals or designated secondary care facilities). Each isolation room was provided with a pulse oximeter for daily self-measurement of vital signs. Each resident was provided with their own thermometer. Most residents owned internet-enabled mobile phones. Residents without a device were advised to $\log$ in their vital signs with the assistance of their fellow roommate's devices. Residents were also educated on basic hand hygiene and provided with sanitisers to do so.

\section{VSM chatbot platform iteration, dashboard and monitoring}

We collaborated with a Singapore-based health technology start-up to develop a mobile health solution to assist in the remote self-monitoring of vital signs including temperature, heart rate and oxygen saturation. Multiple testing sessions were conducted with dormitory residents by the authors, with iterative improvements deployed by software engineers. Most of these were targeted at improving the user interface to increase its intuitiveness. The platform was built with the following principles:

1. Accessibility: we used messaging applications that migrant workers were familiar with, in their native language. Teleconsultations were conducted through the same platforms, via a three-way call with a volunteer translator.

2. Safety for dormitory residents: healthcare staff were automatically notified via text message about residents who reported abnormal vital signs, so that prompt action could be taken.

3. Safety for healthcare staff: remote monitoring reduced physical contact time and use of personal protective equipment, while reassuring residents that their health was still being monitored.

4. Cost: the platform used the residents' own mobile devices and standard oximeters and thermometers. Aside from the development and messaging costs, there were no recurring costs.

We designed a self-reporting form with the following questions accompanied by pictorial representations, administered in the resident's language of choice:

1. Do you have chest pain or breathlessness?

2. Please enter your temperature.

3. Please enter your heart rate.

4. Please enter your oxygen level.

5 . Do you have chest pain or breathlessness?

Question 5 was only asked in dormitory 1 due to the preference of the managing medical teams.

The residents were asked for their mobile numbers and names the first time they completed the form. Mobile numbers were used by clinical teams as unique identifiers to monitor the trends of residents' vital signs as part of routine clinical care. Identifiers including mobile number were removed and the data were anonymised for the purpose of data analysis. We worked with the residents and iterated the platform based on their feedback to address language barriers and cultural differences in the way they interact with their mobile phones. The eventual solution consisted of a chatbot ('SGDormBot') deployed on social messaging platforms (predominantly WhatsApp, but also included Facebook Messenger and Telegram) with a hyperlink to the self-reporting form above. Subsequent reminders were sent via the same messaging platform to the resident two times per day, until day 14 of illness or until the resident was transferred to a different facility. Internet access was made freely available to all residents. 
Residents were educated on acceptable readings when being taught how to use the VSM platform on transfer to the isolation areas of the dormitories. The vital signs entered by residents flowed automatically to a secure dashboard. The use of filters and pivot tables allowed healthcare workers to view entries categorised by time, individual or abnormality. A safety precaution, in the form of an automated text message sent directly to rostered off-site physicians, was built to alert healthcare workers to residents in need of urgent medical attention. Alerts were sent if the resident fulfilled any of the following criteria: (1) answered yes to chest pain or breathlessness; (2) heart rate more than $120 \mathrm{bpm}$; or (3) oxygen saturation on room air of less than $95 \%$.

Alerted physicians could access the dashboard on their computers or mobile phones to observe vital signs and trends and, if appropriate, initiate a teleconsultation via WhatsApp messaging or WhatsApp video call. Volunteer interpreters helped to create a template of translated phrases, which could be used for the WhatsApp messages. For example, 'please recheck your oxygen level' was translated into Bengali, Tamil, Hindi and Mandarin and used by the medical team for the initial messages. The languages for translation were chosen based on the most commonly spoken languages used by residents. Three-way video calls could be arranged with volunteer translators fluent in the residents' native language. These volunteers were the same ones who pre-translated the phrases used for messaging. When video consults were required, the dormitory resident was first messaged in private by a medical professional using a pre-translated message to ask for their consent for a third-party interpreter to join the conversation. There were no objections to the consults. Third-party interpreters were added to the calls by the medical professional. Both the medical professional and interpreters were off-site during the teleconsultation. Dedicated SIM cards were used to protect the personal phone numbers of the medical professionals and interpreters. It was not possible to ensure privacy from other residents in the shared dormitory room due to isolation policies and strict movement restrictions in place in isolation areas. Residents were aware of this limitation before starting the video consult. All parties involved in the consult were informed of and understood their legal and ethical obligations to maintain patient confidentiality. Residents who were unwell were either conveyed to acute care hospitals via emergency ambulance or identified for on-site medical review the following day, as directed by the physician.

\section{Data collection and analysis}

Data were collected retrospectively encompassing (a) demographics, including age, sex and ethnicity; (b) comorbidities: presence or absence of hypertension and diabetes; and (c) vital sign reports. No patientidentifiable data were collected. The total number of unique residents and the vital sign reporting frequency were extracted from the VSM system. Engagement rate was defined as the total number of residents registered on the VSM platform with at least one reading, over the total number of residents with COVID-19. Temperature, heart rate and oxygen saturation data were also extracted and analysed. A subgroup analysis was done on readings that triggered the alert system. We tabulated the outcomes of the alerts, and the percentages that resulted in teleconsultations and in escalation of care. Data analysis was done using RStudio, V.1.1.383.

\section{Patient and public involvement}

Patients and the public were not involved in the design, conduct, reporting or dissemination plans of our research.

\section{Ethical Considerations}

This study was approved by our institutional ethics review board. A waiver of informed consent was also approved for this study, as this was a retrospective review of routine medical care provided to the patients.

The authors of this paper were voluntarily involved in the enhancement and deployment of the platform to provide clinical care to patients in a setting in which no infrastructure existed. The primary objective was to enable care provision. There was no direct involvement by the chatbot developer in the study or manuscript.

\section{RESULTS}

\section{Patient characteristics}

From 1 May 2020 to 26 May 2020, 800 of the 931 COVID-19 positive residents across the two dormitories used the VSM platform to log a total of 12511 discrete episodes of vital signs. Patient characteristics are shown in table 1. All the residents were men and the mean age was $33 \pm 6.8$ years. The majority were Bangladeshi $(57.3 \%)$ or Indian $(30.2 \%)$. There was a low prevalence of hypertension and diabetes mellitus.

\section{Engagement rate and vital signs}

Of the COVID-19-positive residents across both dormitories, $85.9 \%$ engaged with the platform at least once. The number of residents reporting and the total number of COVID-19-positive residents on a daily basis is shown in figure 1, representing a high daily utilisation rate. The overall mean temperature, heart rate and oxygen saturations were within normal range. Most of the alerts were due to abnormal oxygen saturation readings. $11(0.1 \%)$ temperature recordings exceeded $38.0^{\circ} \mathrm{C}, 109(0.9 \%)$ heart rate recordings exceeded 120 beats per minute and $246(2.0 \%)$ oxygen saturation recordings were below $95 \%$ on ambient air. There were a total of $90(0.7 \%)$ reports of chest pain or breathlessness (table 2).

\section{Outcome of alerts}

Outcomes are shown in figure 2. Out of 372 alerts, $132(35.5 \%)$ residents rechecked their vital signs and reported a normal reading without prompting. A total of $96(25.8 \%)$ teleconsultations were initiated, of which 37 were done through WhatsApp text messaging and 59 
Table 1 Profile of all COVID-19 positive residents offered VSM, and unique residents registered onto VSM (1-26 May)

\section{Dorm residents with COVID-19} $\mathrm{n}=931$

\begin{tabular}{lr}
\hline $\begin{array}{l}\text { Age, mean (SD) } \\
\text { Male, } \mathrm{n}(\%)\end{array}$ & $33.0(6.8)$ \\
$\begin{array}{l}\text { Comorbidities, } \mathrm{n}(\%) \\
\text { Hypertension }\end{array}$ & $9(1.0)$ \\
\hline Diabetes & $13(1.4)$ \\
\hline Ethnicity, $\mathrm{n}(\%)$ & \\
\hline Bangladesh & $533(57.3)$ \\
\hline Indian & $281(30.2)$ \\
\hline Chinese & $55(5.9)$ \\
\hline Myanmar & $13(1.4)$ \\
\hline Thai & $4(0.4)$ \\
\hline Vietnamese & $1(0.1)$ \\
\hline Not reported & $44(4.7)$ \\
\hline Dormitory, n(\%) & \\
\hline Dormitory 1 & $664(71.3)$ \\
\hline Dormitory 2 & $267(28.7)$ \\
\hline Registered on VSM, (engagement rate in \%) \\
\hline Dormitory 1 & $574(86.4)$ \\
\hline Dormitory 2 & $226(84.6)$ \\
\hline
\end{tabular}

VSM, vital sign monitoring.

through WhatsApp video call. Following teleconsultation, $7(1.8 \%)$ cases were escalated to emergency services and $18(4.9 \%)$ were triaged to an earlier physical medical review on-site. Of these 18, 4 were subsequently sent to hospital after medical review. There were no deaths

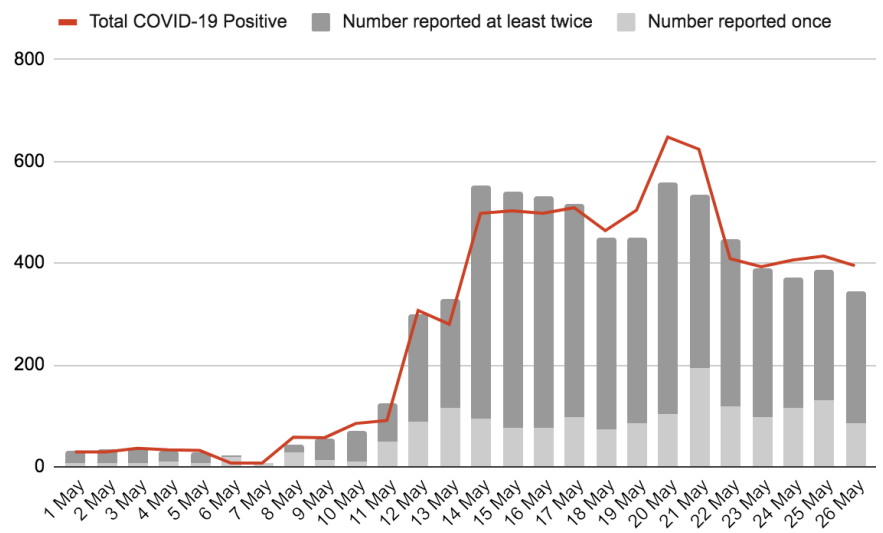

Figure 1 Compliance chart. The red line represents the total number of COVID-19 affected residents by day. The bar chart represents the number of residents who reported at least one reading into SGDormBot by day. *Some residents continued to report daily despite having been removed from the system, accounting for the days when total number of residents reporting exceeded the total number of COVID-19 residents. †Increase in residents from 12 May onwards due to implementation at a second dormitory.
Table 2 Profile of all vital signs entries

$\begin{array}{ll}\begin{array}{ll}\text { Total number } \\ \text { of entries }\end{array} & \begin{array}{l}\text { Number of } \\ \text { alerts } n=372\end{array} \\ n=12511 & (3.0 \%)\end{array}$

\begin{tabular}{|lcc|}
\hline Temperature & & \\
\hline Number reported, $\mathrm{n}(\%)$ & $12271(98.1)$ & $365(98.1)$ \\
\hline Mean (SD) & $36.4(0.4)$ & $36.5(0.5)$ \\
\hline$<37^{\circ} \mathrm{C}, \mathrm{n}(\%)$ & $11652(93.1)$ & $309(83.1)$ \\
\hline 37 to $<38^{\circ} \mathrm{C}, \mathrm{n}(\%)$ & $608(4.9)$ & $751(13.7)$ \\
\hline$\geq 38^{\circ} \mathrm{C}, \mathrm{n}(\%)$ & $11(0.1)$ & $5(1.3)$ \\
\hline Heart rate & & \\
\hline Number reported, $\mathrm{n}(\%)$ & $12511(100)$ & $372(100)$ \\
\hline Mean (SD) & $86.7(11.8)$ & $94.4(18.6)$ \\
\hline$<60$ bpm, $\mathrm{n}(\%)$ & $40(0.3)$ & $2(0.5)$ \\
\hline 60 to $<100$ bpm, $\mathrm{n}(\%)$ & $10660(85.2)$ & $269(72.3)$ \\
\hline 100 to $<120$ bpm, $\mathrm{n}(\%)$ & $1702(13.6)$ & $40(10.8)$ \\
\hline$\geq 120$ bpm, $\mathrm{n}(\%)$ & $109(0.9)$ & $61(16.4)$ \\
\hline Oxygen saturation & & \\
\hline Number reported, $\mathrm{n}(\%)$ & $12511(100)$ & $435(100)$ \\
\hline Mean (SD) & $97.3(1.8)$ & $92.4(6.5)$ \\
\hline$<95 \%, \mathrm{n}(\%)$ & $246(2.0)$ & $241(64.8)$ \\
\hline
\end{tabular}

Chest pain or breathlessness*

Yes, $\mathrm{n}(\%) \quad 90(0.7) \quad 90(35.9)$

${ }^{*}$ Chest pain or breathlessness only asked in dormitory 1 due to managing physician preference. There was a total of 10426 entries, with the remainder answering "no" to the question.

reported. No adverse events were recorded in residents who were not triggered via the VSM platform.

\section{DISCUSSION}

Implementing a community-based vital signs selfmonitoring system in a culturally and linguistically distinct migrant worker population with COVID-19 was associated with a high engagement rate. Among 931

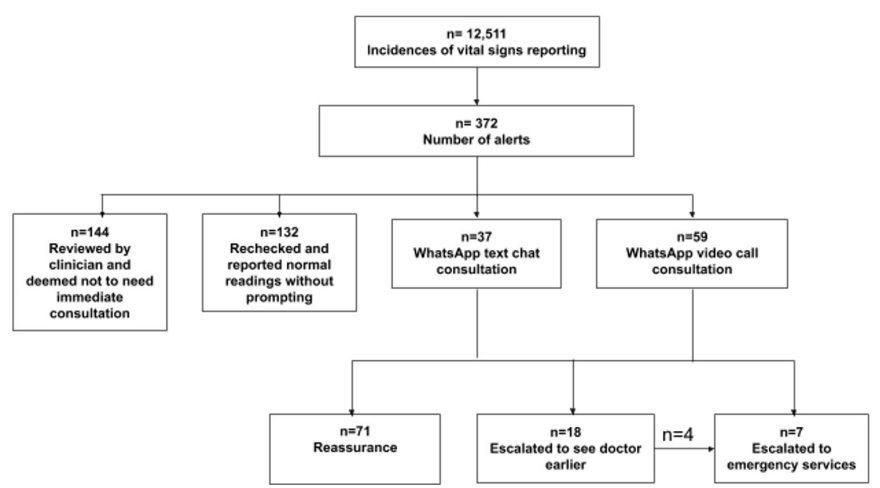

Figure 2 Results of alerts. Reasons for deciding not to need immediate consultation included: having just been reviewed at the medical post, borderline tachycardia or similar complaints previously. 
residents, $85.9 \%$ engaged with the system, enabling safe monitoring and identification of a minority of residents at risk of deterioration.

Telemedicine initiatives play a crucial role in global pandemics. ${ }^{8} 9$ They are cost-effective, scalable, reduce exposure, address provider shortages ${ }^{10}$ and enable remote logistics, ${ }^{5}$ while achieving satisfaction with the majority of patients. ${ }^{11}$ In the United Kingdom, 'virtual wards', where patients with COVID-19 are managed at home, resulted in over 300 bed days saved in 3 weeks. The initiative was found to be safe, with a $5 \%$ readmittance rate and no deaths. ${ }^{12}$

Most remote VSM initiatives have been delivered in high resource settings, ${ }^{13}$ either involving specialised equipment or downloading custom-built apps. In contrast, COVID-19 disproportionally affects people with disadvantaged backgrounds,${ }^{14}{ }^{15}$ with international migrant worker ${ }^{16} 17$ and refugee $^{1819}$ communities reported as among the most marginalised in the COVID-19 fight. Although mobile health platforms have been used in low-resource and medium-resource settings for cardiovascular risk reduction, ${ }^{20}$ mental health ${ }^{21}$ and HIV care,${ }^{22}$ to our knowledge, there have been no reported use in monitoring COVID19-positive patients in such settings.

Our strategy was to combine iteration, education, collaboration with stakeholders and trust-building to deploy a solution that would benefit the dormitory residents, and that they would use. The availability of volunteer translators for teleconsultation improved communication, enhanced the accuracy of medical histories and built trust in the system.

Technological literacy proved one of our biggest challenges at the outset. Most telemedicine solutions have been created in a cultural context that these populations are not familiar with. Residents found recognising hyperlinks, scanning Quick Response (QR) codes, transcribing universal resource locators (URLs), navigating websites and scrolling through webpages challenging. The use of familiar messaging apps allowed visual prompts such as emojis, videos and photos to be used (online supplemental appendix A). We also deployed a form with simple, pictorial questions with binary answers and automatic progression. We modified the flow of the form to match the display orientation of the pulse oximeters provided, which was essential for accurate data input from the residents (online supplemental appendix B and C). In conjunction with a single, short teaching session, this proved to be the most successful means of engaging the residents to use the system.

Co-development with clinicians and software engineers allowed us to customise the system for ground teams by modifying alert timing, threshold and content. Together, we also designed a clinically-relevant monitoring dashboard that enabled the healthcare team to instantly review trends over time and communicate. Importantly, co-development gave clinicians a sense of ownership over the system and allowed the system to be adapted to workflows on the ground, rather than vice versa.
This study has several limitations. First, the setting was solely within migrant worker dormitories and not in other vulnerable populations, which may have their own unique challenges. However, these principles may be applied to deliver telemedicine solutions in similar settings such as refugee camps and prisons, multilingual populations, or to persons with limited technological literacy. Second, the approach required the residents to own smartphones. While this may not be always the case in under-resourced populations, smartphone penetration is on the rise. ${ }^{23} 24$ In areas without access to smartphones, we propose a central, secured device where individuals can key in their recorded vital signs. In some community isolation facilities in Singapore, one iPad (Apple, USA) was secured to a monitoring station and an app installed to allow vital signs to be recorded and uploaded to a secure cloud server. A similar concept could be applied for a shared smartphone with WhatsApp pre-installed. Other possibilities include installing a landline in a central location, with phone calls at pre-set times to the isolation areas so that residents can relay their vital signs to an off-site operator or a sequential messaging system, where residents with mobile phones can key in their vital signs in response to short message service (SMS) prompts.

Third, while our data showed good engagement rate, we were unable to report the exact uptake rate as some patients continued to report their vital signs after transferring out of the dormitory, or were transferred out at different times in the day, resulting in a dynamic denominator over a single day. The daily patient numbers were collected at the start of the day, before transfers in and out of the isolation areas. Fourth, while our data show good engagement and compliance, the lack of a control group made it difficult to conclude whether patients who were teleconsulted would have sought help from alternative means if the solution did not exist. Finally, we were unable to assess the exact accuracy of the self-reported vital signs. Safeguards against inaccurate reporting in our platform included prompts to re-enter if an invalid number (e.g., $110 \%$ for oxygen saturation) was entered. All other plausible abnormal results outside the pre-defined acceptable range resulted in a medical intervention. As the objective was to provide safe care, inaccuracies within the acceptable range were not specifically sought or corrected. We considered that residents may be fearful of keying in abnormal vital signs due to fear of what might happen subsequently. However, residents were regularly reassured that the purpose of the platform was to ensure their safety and timely access to emergency care in hospital, should the need arise.

\section{CONCLUSION}

The serious challenges imposed by the COVID-19 pandemic have accelerated the development of telemedicine. In this study, we have shown how cultural, language and low technological literacy in an underresourced population can be overcome through iteration, 
collaboration and perspective to implement a low-cost mobile health solution. We believe that the lessons learnt can be applied to develop safe and cost-effective telemedicine solutions to increase access to healthcare for marginalised populations.

Correction notice This article has been corrected since it first published. The provenance and peer review statement has been included.

Twitter Wei-Ying Jen @jenweiying

Contributors SQK and W-YJ designed, implemented and refined the monitoring solution with advice from Y-LC. They drafted the manuscript. BMYH, C-YK, DWPC and ZJL assisted with the clinical implementation and remote teleconsultations. Data analysis was done by SQK and reviewed by all authors. All authors revised and edited the manuscript.

Funding This project was supported by a grant by the Temasek Foundation, Singapore.

Competing interests None declared.

Patient consent for publication Not required.

Ethics approval This study was approved by our local institutional ethics review board (National Healthcare Group, Singapore. Domain Specific Review Board, reference number 2020/00703).

Provenance and peer review Not commissioned; externally peer reviewed.

Data availability statement Data are available upon reasonable request. The data is stored in a secure internet-separated hospital computer. Data is available on request to Dr Jen (wei_ying_jen@nuhs.edu.sg).

Supplemental material This content has been supplied by the author(s). It has not been vetted by BMJ Publishing Group Limited (BMJ) and may not have been peer-reviewed. Any opinions or recommendations discussed are solely those of the author(s) and are not endorsed by BMJ. BMJ disclaims all liability and responsibility arising from any reliance placed on the content. Where the content includes any translated material, BMJ does not warrant the accuracy and reliability of the translations (including but not limited to local regulations, clinical guidelines, terminology, drug names and drug dosages), and is not responsible for any error and/or omissions arising from translation and adaptation or otherwise.

Open access This is an open access article distributed in accordance with the Creative Commons Attribution Non Commercial (CC BY-NC 4.0) license, which permits others to distribute, remix, adapt, build upon this work non-commercially, and license their derivative works on different terms, provided the original work is properly cited, appropriate credit is given, any changes made indicated, and the use is non-commercial. See: http://creativecommons.org/licenses/by-nc/4.0/.

\section{ORCID iDs}

Stephanie Q Ko http://orcid.org/0000-0002-1182-5791

Wei-Ying Jen http://orcid.org/0000-0002-9339-3362

\section{REFERENCES}

1 COVID-19 situation report, 2020. Available: https://covidsitrep.moh. gov.sg/ [Accessed 30 May 2020].

2 Yuen S. Stay-home notice for foreign workers, dependants in construction sector extended to may 18, 2020. Available: https:// www.straitstimes.com/singapore/stay-home-notice-for-foreignworkers-dependants-in-construction-sector-extended-to-may-18\#: :
text=Stay \%2Dhome\%20notice\%20for\%20foreign\%20workers\% 2C\%20dependants $\% 20$ in $\% 20$ construction,sector\%20xtended $\%$ 20to\%20May\%2018\&text=The\%20workers\%2C\%20who\%20are\% 20work,until\%20May\%2018\%2C\%2011.59pm [Accessed 6 Jun 2020].

3 Gandhi RT, Lynch JB, del Rio C. Mild or moderate COVID-19. N Engl J Med Overseas Ed 2020;383:1757-66.

4 Berlin DA, Gulick RM, Martinez FJ. Severe COVID-19. N Engl J Med 2020;383:2451-60.

5 Watson AR, Wah R, Thamman R. The value of remote monitoring for the COVID-19 pandemic. Telemed J E Health 2020;26:1110-2.

6 Medina M, Babiuch C, Card M. Home monitoring for COVID-19. Cleve Clin J Med 2020 doi:10.3949/ccjm.87a.ccc028

7 Huang S, Xiao Y, Yan L, et al. Implications for online management: two cases with COVID-19. Telemed J E Health 2020;26:487-94.

8 Ohannessian R, Duong TA, Odone A. Global telemedicine implementation and integration within health systems to fight the COVID-19 pandemic: a call to action. JMIR Public Health Surveill 2020;6:e18810.

9 Rockwell KL, Gilroy AS. Incorporating telemedicine as part of COVID-19 outbreak response systems. Am J Manag Care 2020;26:147-8

10 Doshi A, Platt Y, Dressen JR, et al. Keep calm and log on: telemedicine for COVID-19 pandemic response. $J$ Hosp Med 2020;15:301-4.

11 Annis T, Pleasants S, Hultman G, et al. Rapid implementation of a COVID-19 remote patient monitoring program. J Am Med Inform Assoc 2020;27:1326-30. doi:10.1093/jamia/ocaa097

12 Thornton J. The "virtual wards" supporting patients with covid-19 in the community. BMJ 2020;369:m2119.

13 Mann DM, Chen J, Chunara R, et al. COVID-19 transforms health care through telemedicine: evidence from the field. J Am Med Inform Assoc 2020;27:1132-5.

$14 \mathrm{Ji}$ Y, Ma Z, Peppelenbosch MP, et al. Potential association between COVID-19 mortality and health-care resource availability. Lancet Glob Health 2020;8:e480.

15 Devakumar D, Bhopal SS, Shannon G. COVID-19: the great unequaliser. J R Soc Med 2020;113:234-5.

16 Liem A, Wang C, Wariyanti Y, et al. The neglected health of international migrant workers in the COVID-19 epidemic. Lancet Psychiatry 2020;7:e20.

17 Kluge HHP, Jakab Z, Bartovic J, et al. Refugee and migrant health in the COVID-19 response. Lancet 2020;395:1237-9.

18 Orcutt M, Patel P, Burns R, et al. Global call to action for inclusion of migrants and refugees in the COVID-19 response. Lancet 2020;395:1482-3.

19 Hargreaves S, Zenner D, Wickramage K, et al. Targeting COVID-19 interventions towards migrants in humanitarian settings. Lancet Infect Dis 2020;20:645-6.

20 Piette JD, List J, Rana GK, et al. Mobile health devices as tools for worldwide cardiovascular risk reduction and disease management. Circulation 2015;132:2012-27.

21 Sood M, Chadda RK, Singh P. Mobile health (mHealth) in mental health: scope and applications in low-resource settings. Natl Med J India 2016;29:341-3.

22 Campbell Jl, Aturinda I, Mwesigwa E, et al. The technology acceptance model for resource-limited settings (TAM-RLS): a novel framework for mobile health interventions targeted to low-literacy end-users in resource-limited settings. AIDS Behav 2017;21:3129-40.

23 Silver L. Smartphone ownership is growing rapidly around the world but not always equally, 2019. https://www.pewresearch.org/global/ 2019/02/05/smartphone-ownership-is-growing-rapidly-around-theworld-but-not-always-equally/

24 Statistics on InfoComm and media, 2020. Available: https://www. singstat.gov.sg/find-data/search-by-theme/industry/infocomm-andmedia/latest-data [Accessed 11 Jun 2020]. 